Haes, H. de, Bensing, J. Endpoints in medical communication research, proposing a framework of functions and outcomes. Patient Education and Counseling: 2009, 74(3), 287-294

\begin{tabular}{|l|l|}
\hline $\begin{array}{l}\text { Postprint } \\
\text { Version }\end{array}$ & 1.0 \\
\hline $\begin{array}{l}\text { Journal website } \\
\text { Pubmed link }\end{array}$ & $\underline{\text { http://dx.doi.org.proxy.library.uu.nl/10.1016/j.pec.2008.12.006 }}$ \\
\hline DOI & $\underline{\text { 10.1016/j.pec.2008.12.006 }}$ \\
\hline
\end{tabular}

This is a NIVEL certified Post Print, more info at $h$ ttp://www.nivel.eu

\title{
Endpoints in medical communication research, proposing a framework of functions and outcomes
}

\author{
HANNEKE DE HAES ${ }^{\mathrm{A},}$ AND JOZIEN BENSING ${ }^{\mathrm{B}, \mathrm{C}}$ \\ ${ }^{a}$ Department of Medical Psychology, Academic Medical Centre, Meibergdreef 15, 1105 AZ \\ Amsterdam, The Netherlands \\ ${ }^{\mathrm{b}}$ NIVEL, Netherlands Institute for Health Services Research, Utrecht, The Netherlands \\ ${ }^{c}$ Department of Clinical and Health Psychology, Utrecht University, The Netherlands
}

\begin{abstract}
Objective: The evidence base of medical communication has been underdeveloped and the field was felt to be in need for thorough empirical investigation. Studying medical communication can help to clarify what happens during medical encounters and, subsequently, whether the behavior displayed is effective. However, before effectiveness can be established, one should argue what functions or goals the communication has and what outcomes are relevant in medical communication research.

Results and conclusions: In the present paper, we first suggest the six function model of medical communication based on the integration of earlier models. The model distinguishes (1) fostering the relationship, (2) gathering information, (3) information provision, (4) decision making, (5) enabling disease and treatment-related behavior, and (6) responding to emotions. Secondly, a framework for endpoints in such research is presented. Immediate, intermediate and long-term outcomes are distinguished on the one hand and patient-, provider- and process- or context-related outcomes on the other. Based on this framework priorities can be defined and a tentative hierarchy proposed. Health is suggested to be the primary goal of medical communication as are patient-related outcomes. Dilemmas are described. Finally, in medical communication research, theory is advocated to link health care provider behavior or skills to outcomes and to connect intermediate outcomes to longterm ones.

Practice implications: By linking specific communication elements to concrete endpoints within the six function model of medical communication, communication will become better integrated within the process of medical care. This is helpful to medical teachers and motivational to medical students. This approach can provide the place to medical communication it deserves in the center of medical care.
\end{abstract}


Haes, H. de, Bensing, J. Endpoints in medical communication research, proposing a framework of functions and outcomes. Patient Education and Counseling: 2009, 74(3), 287-294

\section{INTRODUCTION}

Medical communication is at the heart of medicine. Without good communication neither a diagnosis nor a treatment plan can be established. Moreover, how could advise be given or the emotional implications of disease handled? Still, the quality of medical communication has long been taken for granted. Junior doctors would develop their personal style from watching their teachers' behavior. Over the last decades though, medical communication has been addressed in the literature. Moreover, it became a teaching subject in many medical curricula and attracted the attention of researchers.

What good doctor-patient communication entails has been described primarily in the context of patient-centered medicine. Yet, the ideological base of patient-centered medicine is better developed than its evidence base is [1]. Likewise, the evidence base of medical communication has long been underdeveloped. The need for in-depth research in this area is pressing though. Rather than convincing health care professionals of the relevance of communication skills on ideological grounds, the field will benefit in the long run from gaining precise evidence to substantiate its effectiveness.

Unfortunately, the research addressing medical communication seems to be characterized, first, by the use of a variety of endpoints or outcomes, often chosen without further justification and priorities set among them. This may hamper the interpretation of results and the strength of the evidence. For example, in a large randomized study Kinmonth et al. [2] found a positive effect of a patient-centered communication intervention on patient satisfaction but, at the same time, a negative effect on disease-related parameters. How should such results be evaluated and weighed? Is the intervention investigated to be judged positively or negatively? It is still unclear what priority should be given when findings are contradictory. Secondly, short term and longer term endpoints are not always distinguished explicitly. For example, in a study investigating the effect of communication skills training among oncologists, the intended behavior change was indeed achieved [3]. Such behavior, however, does not necessarily translate into improved patient outcomes. Doctors may learn to use more open questions. Still, if they would use them in the wrong moment or with the wrong person this might even be counterproductive [4]. Thus, the relation between consultation behaviors and longer term outcomes should be clarified before accepting the positive outcome of such trial. Thirdly, communication is often used as a container concept. In many studies, a battery of communication skills is assessed without further differentiation between the communication elements. If a positive result is found in such studies, it remains unclear which of the communication elements have contributed to the effects. Having a shared framework of relevant goals and endpoints among communication researchers, will allow for systematic study of the effects of (elements of) medical communication. More important, it will permit setting priorities among outcomes and, thus, create a stronger basis for building evidence in the field. Such evidence can then support teaching as well as clinical practice.

Ideally, medical communication research will first clarify what happens during medical encounters. Subsequently, it can explain if what happens, i.e., the communicative behavior displayed, is effective or not. However, why some behavior is to be considered effective or ineffective depends on the relation of such behavior to outcomes. Therefore, one needs a framework of relevant outcomes. What outcomes are relevant depends, in turn, on the goals of medical communication. In the current paper, we therefore aim, first, to discuss the goals, or functions, of medical communication. Secondly, we propose a framework for endpoints derived from these goals and a provisional outcome hierarchy. Finally, to further strengthen the evidence base of medical communication, we discuss how theory can contribute to our field. 
Haes, H. de, Bensing, J. Endpoints in medical communication research, proposing a framework of functions and outcomes. Patient Education and Counseling: 2009, 74(3), 287-294

\section{A FRAMEWORK DEFINING GOALS OF THE MEDICAL COMMUNICATION}

Whether medical communication is effective, depends on the goals pursued. What are these goals when the patient and the health care professional are communicating? Different models have described the goals or functions of medical communication (see Fig. 1). Bird and Cohen-Cole [5] were among the first authors to propose a model for the functions of medical communication. They addressed the medical interview and distinguished three basic functions: (1) gathering data, biological and psychosocial, (2) responding to patients' emotions, and (3) educating patients and influencing their behavior. This model has similarities but is not identical to the three function model, that was described by Lazare et al. [6]. They distinguished the need (1) to determine and monitor the nature of the health problem, (2) to develop, maintain and conclude the therapeutic relationship, and (3) to carry out patient education and implementation of treatment plans [6]. De Haes and Teunissen [7] and Smets et al. [8] have described a five function model: (1) relationship building, (2) information exchange, (3) decision making, (4) giving advice, and (5) handling emotions. Recently, Epstein and Street [9] have proposed a framework to guide future research in patient clinician communication in cancer settings. They distinguish six core functions of patient clinician communication: (1) fostering relationships, (2) information exchange, (3) making decisions, (4) enabling self-management, (5) responding to emotions, and (6) managing uncertainty.

\section{[FIGURE 1]}

As becomes evident from Fig. 1, these models show overlap as well as differences. We propose a six function model of medical communication. First, relationship building or fostering the relation is considered in three earlier models. Relevant elements like respect, trust and rapport are necessary components of a therapeutic relationship. Actually, the quality of the relationship between patient and health care provider is now generally assumed to be an essential basis for the quality of health care. Without a good relationship none of the other goals of the medical encounter can be pursued in an optimal manner.

Next, exchange of information is mentioned. Information exchange however, involves in fact both information gathering and information giving. On the one hand, clinicians need information from their patients about symptoms, experience and expectations for establishing a diagnosis and treatment plan. In this case, doctors are rather at the receiving end and patients rather have an information giving role. Patients, on the other hand, need information to understand their illness and treatment, to make decisions and to cope throughout the disease trajectory. When information provision is the main communication goal, the patient is more clearly the receiving and the doctor the providing party. Based on Bird and Cohen-Cole's model and the fact that different communication goals are pursued in these two functions, we prefer to make the distinction between them explicit. Thus, the second function, information gathering refers, as suggested, to accurate data collection, efficient data collection as well as determining the nature of the patients' problem [5]. The third function, information provision refers to the process in which information is conveyed. Information is given for several reasons: it clarifies the patients' health problem, is the basis for decision making, it reduces uncertainty and it supports coping efforts. Recent research has shown that most patients want to be fully informed nowadays [10]. As a fourth function, we distinguish involving the patient in decision making. In both the shared and the informed decision making model, communication is essential to reach an acceptable decision. These models have been increasingly advocated over the last decade [11]. Good decision making was found to lead to better adherence and health [8]. Decisions in which patients participate support their autonomy. Even when patients rather leave a decision to their doctor, the tailoring involved requires effective communicative behavior. A fifth function is the support or promotion of behavior related to the disease and treatment. Patient behavior is mostly relevant to disease management as well as treatment adherence. Also, many life style related 
Haes, H. de, Bensing, J. Endpoints in medical communication research, proposing a framework of functions and outcomes. Patient Education and Counseling: 2009, 74(3), 287-294

behaviors are involved in the promotion of recovery or the prevention of deterioration of health. One can imagine that clinicians often communicate, for example, about taking rest or, on the contrary being active, about medication use, about diet or unfortunate life styles such as smoking and lack of exercise. Bird and Cohen-Cole [5] have talked about educating patients or influencing patients. Epstein and Street [9] have called this function enabling selfmanagement. Yet, the latter also covers helping patients to be more autonomous [9]. This may be beyond the scope of the everyday medical encounter. Given that we assume that behavior is an essential component of this function, we use the term enabling disease and treatment-related behavior. Finally, in the six function model, as in some other ones displayed, responding to emotions is considered to be an essential function of medical communication. Emotions are inherent in the medical context. Disease and treatment often make patients vulnerable and are, as a result, laden with emotions such as anxiety, anger and sadness. Clinicians will not and cannot deny these emotions for several reasons [5]. They may want to relieve distress. Furthermore, emotions may interfere with the other goals of the encounter and should therefore be alleviated. Finally, the detection of emotional problems and adequate referral may be part of their treatment plan.

Epstein and Street [9] mention the reduction of uncertainty as a last function of the communication. Uncertainty, especially in risk communication, is definitely of great importance today, for example in genetic counseling. Yet, in our view, the six function model is more parsimonious and therefore preferable: reducing uncertainly can also be seen as part of the process of information giving or, alternatively, as an ingredient of responding to emotions.

The six functions described are not necessarily independent. As written above, a good relationship will be helpful in reaching a diagnosis, making satisfactory decisions as well as promoting illness-related behavior. Similarly, a shared decision cannot be reached without a patient being well informed. Thus, good decision making is intrinsically linked to good information giving. Yet, information may also be given in the context of explaining the prognosis of illness or preparing for late consequences of treatment. It is, in other words, a separate function too. More importantly, these goals may be reached with different clinical skills. In fact, their dependency or independence may be a question of empirical investigation in itself.

\section{A FRAMEWORK DEFINING ENDPOINTS OF THE MEDICAL COMMUNICATION}

\subsection{Different types of endpoint}

Given these goals, the question is how effectiveness is established. We need an outcome model, connected to the different goals distinguished. Still, the terminology used in the literature is diverse and may be confusing. We therefore first discuss what types of outcomes may be selected.

Outcomes have been defined as: 'observable consequences of prior activity occurring after an encounter, or after some portion of the encounter is completed' [12]. Beckman et al. [12] distinguish between (a) short term outcomes (they mention patient satisfaction or intention to adhere, (b) intermediate outcomes (they mention actual treatment adherence or anxiety reduction), and (c) long-term outcomes (they mention health or quality of life). Epstein and Street [9] distinguish between outcomes within the consultation, outcomes directly after the consultation and outcomes in the longer run. In the literature, short term outcomes are sometimes referred to as 'proximal outcomes' whereas long-term outcomes may also be called 'distal outcomes'. Outcomes can also be defined as relevant to the patient, to the health care provider or to the process, context or organisation, i.e., be implicit in the health care process. Finally, surrogate outcomes are usually intermediate outcomes that have no value of their own, but are assumed to have a direct relation to relevant long-term outcomes and may thus serve as a 'surrogate' for the eventual purpose of the study. For 
Haes, H. de, Bensing, J. Endpoints in medical communication research, proposing a framework of functions and outcomes. Patient Education and Counseling: 2009, 74(3), 287-294

example, time to progression may serve as a surrogate endpoint for survival in advanced cancer. Also, biomarkers may play such role.

In clinical research, the term endpoint is often used rather than outcome. These terms may be used interchangeably. However, as described, an outcome can be any consequence of the encounter. The term endpoint is usually meant, in clinical research, to point to the outcome selected as a criterion for establishing effectiveness of the intervention under study. In clinical study protocols, researchers generally have to define what their primary and secondary endpoints are. Endpoints relate directly to the research question. They are considered to be the study main focus and serve, therefore, as the basis for power calculation. Because the main aim of this paper is to make researchers more conscious of the pathway between targets of the medical encounter, specific communication skills that are theoretically supposed to influence the effectuation of these targets and specific outcomes, we from now on use the term 'endpoint' throughout this paper.

\subsection{A framework for endpoints relevant in medical communication research}

First, we follow the model by Epstein and Street [9] and distinguish between immediate endpoints, intermediate endpoints and longer term endpoints. Immediate endpoints are relevant within the medical encounter. Intermediate endpoints relate to processes that are relevant shortly after the encounter. They may be surrogate endpoints if they are conducive to longer term endpoints. Long-term endpoints are observed, by definition, over a longer time perspective and usually refer to the eventual main outcome of an intervention.

Secondly, endpoints may be patient-, health care provider- or context-related ones. The patient is the focus of health care and, subsequently, the medical encounter. Thus, patientrelated endpoints are of great relevance. Still, without the commitment of health care providers such care could not be given. Therefore, provider-related endpoints are considered important as well. The context, involving the care process or organization as well as financial constraints, is another established element of evaluation [13]. It is thus possible to derive immediate, intermediate and longer term endpoints directly from the functions of the medical encounter distinguished earlier. The endpoints may relate to the patient, the health care provider or the context. With these distinctions in mind, we propose a framework for endpoints in medical communication research (see in Fig. 2). The listing given is obviously not exhaustive. It is meant to substantiate further study and discussion.

\section{[FIGURE 2]}

\subsubsection{Immediate endpoints}

Immediate endpoints are relevant within the medical encounter. They may refer to behavior of the patient or the provider as well as to the level of physiological stress in both parties. For example, to foster the relationship, clinicians may make eye contact. Patients, as a result might feel more at ease, therefore experience less stress as assessed with physiological measures such as heart rate or skin conductance. They may also participate more actively during such encounter if they feel they are treated with respect.

As patients, health care providers may perceive more or less stress during encounters. Interestingly, giving bad news has indeed been associated with stress hormone levels [14]. Ptacek and Eberhardt [15] have argued that the physicians' communicative behavior can be understood as a result of coping efforts to minimize their own discomfort. The communicative behavior or communicative skills themselves may thus be the focus of medical communication research. As indicated earlier, for example, Fallowfield et al. [3] found oncologists' behavior to change as a result of communication skills training. In terms of the health care process, depending on the communication displayed, one might observe a worse or better atmosphere, a more or less efficient goal obtainment, and/or the need for more or less time [16]. 
Haes, H. de, Bensing, J. Endpoints in medical communication research, proposing a framework of functions and outcomes. Patient Education and Counseling: 2009, 74(3), 287-294

As shown in Fig. 2, relevant endpoints can formulated for all six functions described. It may be noted that the behaviors described as immediate endpoints are in fact often seen as the skills that one assumes are appropriate. Indeed, if behavior has proven to be effective, such behavior and skills are synonymous.

\subsubsection{Intermediate endpoints}

Intermediate endpoints are relevant shortly after the encounter. They may be surrogate endpoints. Many examples can be given. A physician building a good relationship may, by displaying desired behaviors, raise trust in the patient. Good information gathering may lead to an improved diagnosis and, possibly, the ordering of less diagnostic tests. Eventually, it will improve the treatment plan. Better information provision will, as a result of the skills used, improve the patients' recall and understanding. It may, also, reduce the seeking of second opinions. Adequate communication can lead to more shared decision making and thus reduce the level of decisional conflict [17]. Similarly, intermediate endpoints can be described for the functions of enabling disease and treatment-related behavior as well as responding to emotions. Addressing the patients' motivation, possibilities and barriers will possibly enhance their likelihood of adopting the desired behavior [18]. Thus, communication can improve treatment adherence [10]. Finally, patients may feel supported if their emotions are responded to.

Patients and doctors do not necessarily agree about the quality of the interaction. In fact, the latter were found to be generally less satisfied than their patients shortly after the consultation [19]. Hence, their judgment has additional value when establishing the quality of care [19]. For health care providers to remain active in the field, they also need motivation. Such motivation might be seriously undermined by aggressive behavior by patients during encounters. Also, less rewarding communicative patterns may lead to an increased sense of fatigue. Eventually, this may result in making errors as could be derived from the study by Tamblyn et al. [20] who found doctors with less communicative competence to be more likely to have been confronted with complaints from patients to medical authorities. Finally, their sense of self-efficacy may improve as a result of having improved communication skills [21].

In terms of the health care process, one would like to investigate whether the quality of communication leads to more efficiency, e.g., by decreasing health care use and expenditures.

It may become clear that intermediate endpoints often have limited value in and of themselves but are important because they are related to long-term endpoints. We will come back to this issue later.

\subsubsection{Long-term endpoints}

As the ultimate aim of medical care is to maximize health, effective doctor-patient communication should lead, in the long run, to better or at least optimal health of patients [22]. Health may be seen as an objective endpoint as well as a subjective, perceived one. The objective health endpoints generally adopted are cure, the disease course or length of survival. Stability or a reduced deterioration of the patients' condition may likewise be relevant. Objective health endpoints are usually assessed with traditional medical parameters. Interestingly, Holloway and Quill [23] have argued that mortality may not always be a valid endpoint. Actually, when decisions are preference sensitive in end of life care, good communication may lead to shorter rather than longer life.

Subjective or perceived health is generally referred to as quality of life (see for an overview [24]). Quality of life is usually seen as a patient reported outcome measure of disease and treatment-related consequences. It may cover physical function and symptoms, mental health or psychological distress as well as social concomitants of disease and treatment. Alongside, the overall evaluation of a patient's life is often covered. Numerous instruments have been 
Haes, H. de, Bensing, J. Endpoints in medical communication research, proposing a framework of functions and outcomes. Patient Education and Counseling: 2009, 74(3), 287-294

developed to assess patient's quality of life in a generic or in a disease specific manner [24]. Ideally, good communication will lead to improved objective or subjective health. Finally, it may also improve the patients adjustment to their disease and its consequences.

As health care providers are essential in the provision of health care, their motivation and commitment in the short term are important but their health in the long run even more. If styles of communication or communicative competence would lead to more burn out among clinicians this would undermine the quality of care. Generally, one distinguishes emotional exhaustion, personal accomplishment as well as depersonalization [25]. Burn out among medical specialists is related to both their level of stress and job satisfaction [26]. Thus, it may depend on their communicative practice. Zantinge et al. [27] indeed found that general practitioners with high levels of burnout showed less patient-centered communication.

In the long run, the quality of communication may well be of great relevance to the health care institute's image and, as a result, its position in the market. Therefore, patient satisfaction may be of great importance. Unfortunately, the relation between medical communication and the eventual costs has rarely been investigated. Interestingly, a recent study investigating the effectiveness of the provision of an end of life conversation with terminal patients' turned out to a reduced use of advanced treatment modalities [28].

\subsection{Setting priorities, a proposal}

As argued above, medical communication research is meant to clarify what happens during the medical encounter and explain, on the basis thereof, how the behavior displayed relates to relevant endpoints. To be able to weigh such endpoints, priorities have to be set. We suggest some arguments as building blocks for such hierarchy.

First, as stated, the ultimate aim of medical care is producing optimal health. Therefore, effective doctor-patient communication should lead, first, to better health eventually [22]. Ideally, health is therefore the main endpoint of good medical communication in the long run. For example, as a result of high quality communication, the diagnostic interview may be improved and a better diagnosis established (=immediate endpoint) and treatment may be tailored to the patients' capacities and therefore be more adequate (=intermediate endpoint). It may thus lead to improved health (=long-term endpoint).

Secondly, intermediate endpoints are meant to lead to health rather than necessarily being healthy themselves. If good communication leads to better treatment adherence, it may eventually result in improved health. If a doctor communicates in a manner that is conducive to trust, the patient may be inclined to better follow the advice given and take, e.g., the medicines proposed. The same goes for communication leading to the adoption of a life style that enhances the patient's health. For example, the use of motivational interviewing techniques is a communication strategy that focuses on patients' motivation on the one hand and patients' self-efficacy on the other [18]. In other words, generally speaking, immediate endpoints should lead to intermediate ones and these should, in turn, improve the long-term endpoints, being objective or subjective health.

Thirdly, as argued, health care cannot be given without the commitment of health care providers; clinicians, nurses and others. Their long-term commitment and health are therefore of primary importance also. Still, the patients' health is seen as the focus of health care and therefore even more important. In other words, it is therefore of higher priority. Taken together, these arguments imply that, first, objective and subjective health is given priority over other endpoints. Secondly, long-term endpoints are given priority over immediate or intermediate ones. Thirdly, the quality of health care is first served by patientrelated endpoints rather than provider-related or context-related endpoints. As will be argued later, this does not imply that endpoints lower in the hierarchy cannot be important for communication research.

\subsection{Some second thoughts on priority setting}

We have proposed an impetus to the collection of evidence concerning the effectiveness of medical communication by discussing what endpoints are relevant in this research field. We 
Haes, H. de, Bensing, J. Endpoints in medical communication research, proposing a framework of functions and outcomes. Patient Education and Counseling: 2009, 74(3), 287-294

have suggested some rules for establishing the hierarchy among them. As usual, however, life is more complicated. Therefore, some caveats can be discussed.

First, we have given a large weight to long-term endpoints, especially health as this is in fact the main rationale for health care anyway. However, it should be noted that 'objective' health and quality of life are influenced by many other factors than communication only. They obviously depend on the previous disease and the treatment of the patient. Also, some patients will be more positive in self-reporting health than others anyway. As a result it is difficult to establish the effect of communication on health, especially when studies focus on a single consultation and encounter.

Secondly, it is therefore of importance to investigate the relationship between immediate, intermediate and long-term endpoints. If such relationship has become obvious, the assessment of intermediate endpoints may be as valuable as assessing long-term ones. If it is not, the relevance of intermediate or immediate endpoints diminishes likewise. For example, stimulating patients with cardio-vascular disease to stop smoking will substantially reduce their risk of a recurrence. Thus the cessation rate would be an important outcome parameter when testing communicative interventions meant to promote smoking cessation [29]. At the same time, if smoking cessation is ineffective in altering the course of advanced lung cancer, such interventions could actually be seen in a negative, even inhumane way.

Thirdly, the importance or weight of endpoints may depend on preferences. Whether objective health, disease cure or an improved disease course is to be preferred over subjective health or well being is a matter of individual preferences. At some point patients may want to strive for quality of life rather than receiving life prolonging treatment. Therefore, this argument may have to be viewed with caution in some cases. Likewise, patients may sometimes prefer not to adhere to treatment or life style advice and take the risks for granted. If that is in their interest in any other respect, non-adherence may indeed be more important than adherence.

Fourth, the different endpoints are not always congruent. Patients and doctors may have contradictory goals. For example, a doctor may wish to stick to his time schedule whereas a patient may want to have time to express concerns. The question then is: does the patient always have priority? Obviously, the clinician has no limitless availability and, at the same time, the patients' concerns are not necessarily relevant to the medical encounter. In such case the doctor's agenda may have priority over the patients'. Yet, our choice for putting patient endpoints first, implies that alternatives have to be made explicit. Likewise, within the medical consultation, goals are not necessarily congruent. For example, information giving may lead to emotional distress whereas one of the clinicians' goals may be to relieve such distress. Yet, this may be valid because one assumes that in the longer run, such information is to be preferred over short term distress. This means, in fact, that goals have to be constantly weighed.

Fifth, the level of health care expenditures, a process- or context-related endpoint, has a special place in priority setting. It is obvious that if some kind of communication leads to reduced costs while having the same or even an improved impact on patient- or providerrelated endpoints, such communication is preferable. At the same time, even though one wishes costs to be an inferior consideration, it sets limits to what can be done. Whether extra costs can be generated for a specific communicative intervention, is a matter of political debate.

Sixth, our proposal implies that patient satisfaction is less important than the patients' health. Indeed, a patient that is satisfied with an incompetent doctor may have to be warned rather than congratulated. Yet, in some market oriented systems, patient satisfaction is of prime relevance for evaluating provider performance and quality of care.

Finally, what is to be studied does obviously depend on the research question. For example, a researcher looking at the sequence of behavior, such as the physicians' recognition of patient cues, may not look at patient health as an outcome variable but rather at physician behavior first [30]. Subsequently, that researcher might investigate the sequence of patient 
Haes, H. de, Bensing, J. Endpoints in medical communication research, proposing a framework of functions and outcomes. Patient Education and Counseling: 2009, 74(3), 287-294

behavior and study how that relates to the type of the clinicians' interventions. Yet, such research must search for a rationale, i.e., clarify why responding to cues is of relevance to the field of medical communication and may contribute to the empirical strength thereof.

\section{THE ROLE OF THEORY IN MEDICAL COMMUNICATION RESEARCH}

A good theory sets a framework for the substantiation of relations and predictions. It is, as given in the Oxford English Dictionary, '(1) a system of ideas intended to explain something, especially based on general principles independent of the thing to be explained, (2) a set of principles on which an activity is based' [31]. Interestingly, communication researchers have often departed from a set of principles, such as that patient centeredness should be pursued. Still, they have, so far, not developed a consistent framework for explaining 'why' (the mechanism) and 'how' (the pathway) certain specified communication elements would succeed in reaching the articulated endpoints. Yet, as we suggested a framework of functions and endpoints, theory can be useful. As shown in Fig. 3, theory may first help to predict what skills or behaviors during the medical encounter will promote other relevant ones. Secondly, it can predict or explain how such behaviors relate to intermediate endpoints. Thirdly, theory can link intermediate endpoints to long-term ones.

[FIGURE 3]The question thus is how these endpoints can be explained and predicted. We want to present three examples which show how theory can help to understand the pathway from target via communication to specified endpoints. The first example is Rogerian theory of 'unconditional positive regard' [32]. Many training programmes on medical communication are implicitly or explicitly based on this theoretical approach. The overall aim of communication skills based on Rogerian theory is: providing room for the patient to disclose his/her worries and emotions [33]. Active listening, paraphrasing, showing empathy and the deliberate use of silence are important ingredients [34]. This theory could be helpful in three of the six functions that we have distinguished in medical encounters: (1) fostering the relationship, (2) gathering information, and (3) responding to emotions. With regard to the other three functions, Rogerian-based communication is not sufficient to reach the specified targets and could even be counterproductive, because it does not assist the patient in gaining self-control, better adherence or changing wrong habits [35]. Fig. 2 also shows that the immediate, intermediate and long-term endpoints are slightly different for the three functions in which Rogerian theory is thought to be helpful, thus enabling very precise testing of the value of specified communication elements for the different functions.

The second example concerns the theoretical background of information provision. Information provision is theoretically linked to intermediate endpoints such as recall and understanding. Theories describing cognitive processing may be helpful. At the same time, cognitive processing is influenced under conditions of stress. Thus, knowledge and theories about the function of memory, the level of stress and its impact on the way people in general and patients in particular recall information is helpful in predicting the effectiveness of certain information giving behaviors [36]. Subsequently, one should understand how and under what circumstances recall of information is related to a sense of control or, rather, to a higher level of uncertainty. Among patients low on monitoring giving too much information may have negative rather than positive effects [37].

Thirdly, Miller and Rollnick [18] have described behaviors intending to promote desired behavior change. These behaviors include assessing the patients' motivation and addressing their self-efficacy. Their approach is closely linked to health behavior change theory as well as the stages of change model defined by Prochaska et al. [38]. These theories and models can help to formulate hypotheses about the likelihood that certain skills may lead to enhanced motivation and self-efficacy of patients. And thus, in the long run, their life style change. 
Haes, H. de, Bensing, J. Endpoints in medical communication research, proposing a framework of functions and outcomes. Patient Education and Counseling: 2009, 74(3), 287-294

Thus, when theories have been selected, hypotheses and alternative hypotheses can be formulated to predict the effectiveness of clinicians’ skills and guide empirical study.

\section{CONCLUSION}

Although in much of the literature on medical communication a compelling case is made about the relevance of adequate communication for high quality care, the evidence base of this argument is underdeveloped. In order to be taken seriously, the field of medical communication needs more thorough empirical investigation. Studying medical communication can help to clarify what happens during medical encounters and, subsequently, whether the behavior displayed is effective. However, before effectiveness can be established, one should argue what the functions or aims of the communication are and what endpoints are relevant in medical communication research. We have therefore suggested the six function model of medical communication, distinguishing (1) fostering the relationship, (2) gathering information, (3) information provision, (4) decision making, (5) enabling disease and treatment-related behavior, and (6) responding to emotions. Secondly, a framework for endpoints in such research is presented. Immediate, intermediate and longterm endpoints are distinguished on the one hand and patient-, provider- and process- or context-related endpoints on the other. Based on this framework priorities could be defined and a tentative hierarchy proposed. Health is suggested to be the primary goal of medical communication as are patient-related endpoints.

Dilemmas are described however. The patients' objective health parameters or subjective health is influenced by many more factors than the medical encounter: their disease state, genetic disposition, personality and coping style. These limit the possibility of finding direct effects of communication on health. Secondly, the relationship between immediate, intermediate and long-term endpoints should be taken into account. If such relation is absent, intermediate endpoints may not be relevant at all. Thirdly, patient preferences may have an impact on the weight to be given to intermediate or long-term endpoints and have to be taken into account. Fourth, we have argued that providers' and patients' related endpoints are not necessarily congruent. If so, the weight to be given to both may have to be argued differently. Fifth, the level of health care expenditures constitutes a constraint to any process in which communication takes place. Unfortunately, little research has supported the relationship between medical communication, health care costs and intermediate or longterm endpoints. Such investigation might be very useful in supporting the relevance of medical communication. Finally, in medical communication research, theory is advocated to link health care provider behavior or skills to endpoints and to connect intermediate endpoints to long-term ones.

Only by disentangling the container concept in medical communication and by articulating the hypothesized relationship between specified communication functions and elements and concrete endpoints (including the assumed mechanisms and pathways), we have the chance to bring the field of medical communication into the area of evidence-based medicine.

\subsection{Practice implications}

It has been suggested that nothing is more practical than a good theory. We have made a plea for a more precise and critical approach in medical communication research. Defining functions and endpoints and connecting those to theory will improve our understanding of the effectiveness of communicative behavior. Eventually, this will be of uttermost importance to teaching and clinical practice. It will enhance the specificity of our description of effective communication. Moreover, the acceptance of communicative skills training to students and professionals will be increased as will the precision of such training. Moreover, in the longer run, patients will profit from the improved competence of health care providers to communicate with them and promote their health and well-being. 
Haes, H. de, Bensing, J. Endpoints in medical communication research, proposing a framework/ of functions and outcomes. Patient Education and Counseling: 2009, 74(3), 287-294

\section{CONFLICT OF INTEREST STATEMENT}

None of the authors have a conflict of interest that could inappropriately influence or be perceived to influence this manuscript.

\section{ACKNOWLEDGEMENT}

The authors would like to thank Drs. Robert Hulsman and Ellen Smets as well as the anonymous reviewers for their helpful comments to an earlier version of this manuscript.

\section{REFERENCES}

[1] J. Bensing, Bridging the gap, the separate worlds of evidence based medicine and patient centered medicine, Patient Educ Couns 39 (2000), pp. 17-25.

[2] A.L. Kinmonth, A. Woodcock, S. Griffin, N. Spiegal and M.J. Campbell, Randomised controlled trial of patient centred care of diabetes in general practice: impact on current wellbeing and future disease risk. The diabetes care from Diagnosis Research Team, Brit Med J 317 (1998), pp. 1202-1208.

[3] L. Fallowfield, V. Jenkins, V. Farewell, J. Saul, A. Duffy and R. Eves, Efficacy of a cancer research UK communication skills training model for oncologists: a randomised controlled trial, Lancet 9307 (2002), pp. 650-656.

[4] H. De Haes, Dilemma's in patient centeredness and shared decision making: a case for vulnerability, Patient Educ Couns 62 (2006), pp. 291-298.

[5] Bird J, Cohen-Cole SA. The three function model of the medical interview. In: Hale MS, editor. Methods in teaching consultation liaison-psychiatry, Adv Psychosom Med, Basel, Karger 1990;20:65-88.

[6] A. Lazare, S.M. Putnam and M. Lipkin, Three functions of the medical interview. In: Lipkin, Putnam and Lazare, Editors, The medical interview. Clinical care, education and research, Springer, New York/Heidelberg (1995).

[7] H. de Haes and S. Teunissen, Communication in palliative care: a review of recent literature, Curr Opin Oncol 17 (2005), pp. 345-350.

[8] E. Smets, M. van Zwieten and S. Michie, Comparing genetic counseling with non-genetic health care interactions: two of a kind?, Patient Educ Couns 68 (2007), pp. 225-234.

[9] R.M. Epstein and R.L. Street, Patient-centered communication in cancer care: promoting healing and reducing suffering (NIH Publication No.07-6225), National Cancer Institute, Bethesda, MD (2007).

[10] V. Jenkins, L. Fallowfield and J. Saul, Information needs of patients with cancer: results from a large study in UK cancer centres, Br J Cancer 84 (2001), pp. 48-51.

[11] C. Charles, A. Gafni and T. Whelan, Shared decision making in the medical encounter: what does it mean?, Soc Sci Med 44 (1997), pp. 681-692.

[12] H. Beckman, S.H. Kaplan and R. Frankel, Outcome-based research on doctor-patient communication: a review. In: M.A. Stewart and D.L. Roter, Editors, Communicating with medical patients, Sage Publications, Newbury, Park, CA (1989).

[13] A. Donabedian, Evaluating the quality of medical care, Milbank Q 83 (2005), pp. 691721.

[14] S. van Dulmen, F. Tromp, F. Grosfeld, O. ten Cate and J. Bensing, The impact of assessing simulated bad news consultations on medical students' stress response and communication performance, Psychoneuroendocrinology 32 (2007), pp. 943-950.

[15] J.T. Ptacek and T.L. Eberhardt, Breaking bad news: a review of the literature, J Am Med Assoc 276 (1996), pp. 496-502.

[16] M. Deveugele, A. Derese, A. van den Brink-Muinen, J. Bensing and J. De Maeseneer, Consultation length in general practice: cross sectional study in six European countries, BMJ 325 (2002), p. 472.

[17] A.M. O'Connor, D. Stacey and F. Légaré, Coaching to support patients in making decisions, Brit Med J 2 (2008), pp. 228-229.

[18] W.R. Miller and S. Rollnick, Motivational interviewing (2nd edition), Guildford press (2002). 
Haes, H. de, Bensing, J. Endpoints in medical communication research, proposing a framework/ of functions and outcomes. Patient Education and Counseling: 2009, 74(3), 287-294

[19] L.C. Zandbelt, E.M. Smets, F.J. Oort, M.H. Godfried and H.C. de Haes, Satisfaction with the outpatient encounter: a comparison of patients' and physicians' views, J Gen Intern Med 19 (2004), pp. 1088-1095.

[20] R. Tamblyn, M. Abrahamowicz, D. Dauphinee, E. Wenghofer, A. Jacques, D. Klass, S. Smee, D. Blackmore, N. Winslade, N. Girard, R. Du Berger, I. Bartman, D.L. Buckeridge and J.A. Hanley, Physician scores on a national clinical skills examination as predictors of complaints to medical regulatory authorities, J Am Med Assoc 298 (2007), pp. 993-1001.

[21] J. Ammentorp, S. Sabroe, P.E. Kofoed and J. Mainz, The effect of training in communication skills on medical doctors' and nurses' self-efficacy: a randomized controlled trial, Patient Educ Couns 66 (2007), pp. 270-277.

[22] S.H. Kaplan, S. Greenfield and J.E. Ware, Assessing the effects of physician-patient interactions on the outcomes of chronic disease, Med Care 27 (1989), pp. S110-S127.

[23] R.G. Holloway and T.E. Quill, Mortality as a measure of quality, J Am Med Assoc 298 (2007), pp. 802-804.

[24] P.M. Fayers and D. Machin, Quality of life, the assessment analysis and interpretation (2nd edition), Wiley and Sons, Chichester, England (2007).

[25] C. Maslach, S. Jackson and M. Leiter, Maslach burnout inventory manual, Consulting Psychologists Press, Palo Alto, CA (1996).

[26] M.R. Visser, E.M. Smets, F.J. Oort and H.C. De Haes, Stress, satisfaction and burnout among Dutch medical specialists, CMAJ 168 (2003), pp. 271-275.

[27] E.M. Zantinge, P.F. Verhaak, D.H. de Bakker, J.J. Kerssens, K. van der Meer and J.M. Bensing, The workload of general practitioners does not affect their awareness of patients' psychological problems, Patient Educ Couns 67 (2007), pp. 93-99.

[28] A.A. Wright, B. Zhang, A. Ray, J.W. Mack, E. Trice, T. Balboni, S.L. Mitchell, V.A. Jackson, S.D. Block, P.K. Maciejewski and H.G. Prigerson, Associations between end-oflife discussions, patient mental health, medical care near death, and caregiver bereavement adjustment, J Am Med Assoc 300 (2008), pp. 1665-1673.

[29] L.C. Wiggers, E.M. Smets, J.C. de Haes, R.J. Peters and D.A. Legemate, Smoking cessation interventions in cardiovascular patients, Eur J Vasc Endovasc Surg 26 (2003), pp. 467-475

[30] P. Butow, J. Cockburn, A. Girgis, D. Bowman, P. Schofield, C. D’Este, E. Stojanovski and M.H. Tattersall, CUES Team. Increasing oncologists' skills in eliciting and responding to emotional cues: evaluation of a communication skills training program, Psycho-oncology 17 (2008), pp. 209-218.

[31] Concise In: J. Pearsall, Editor, Oxford English Dictionary (10th edition), Oxford University Press, Oxford (2002).

[32] C.R. Rogers, Client centred therapy, Houghton Miffin, Boston (1951).

[33] J.M. Bensing, Doctor-patient and the quality of care. An observation study into affective and instrumental communication in general practice, NIVEL/Erasmus University, Utrecht/Rotterdam (1991).

[34] A.E. Ivey and M.B. Ivey, Intentional interviewing and counselling. Facilitating client development in a multicultural society (6th edition), Thomson Brooks/Cole, Belmont, USA (2007).

[35] J.M. Bensing, Doctor-patient communication and the quality of care, Soc Sci Med 32 (1993), pp. 1301-1310.

[36] M.S. Tollenaar, B.M. Elzinga, P. Spinhoven and W. Everaerd, Long-term outcomes of memory retrieval under stress, Behav Neurosci 122 (2008), pp. 697-703.

[37] R.G. Hagerty, P.N. Butow, P.M. Ellis, S. Dimitry and M.H. Tattersall, Communicating prognosis in cancer care: a systematic review of the literature, Ann Oncol 16 (2005), pp. 1005-1053.

[38] J.O. Prochaska, C.C. DiClemente and J.C. Norcross, In search of how people change: applications to addictive behaviors, Am Psychol 47 (1992), pp. 1102-1114. 
Haes, H. de, Bensing, J. Endpoints in medical communication research, proposing a framework of functions and outcomes. Patient Education and Counseling: 2009, 74(3), 287-294

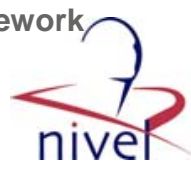

FIGURES AND TABELS

Fig. 1. Development of the six function model of medical communication.

\begin{tabular}{|c|c|c|c|c|c|}
\hline & $\begin{array}{l}\text { Three function } \\
\text { model (Bird \& } \\
\text { Cohen-Cole) }\end{array}$ & $\begin{array}{l}\text { Three function model } \\
\text { (Lazare, Putman \& } \\
\text { Lipkin) }\end{array}$ & $\begin{array}{l}\text { Model of medical communication } \\
\text { functions (de Haes \& Teunissen; } \\
\text { Smets, van Zwieten \& Michie) }\end{array}$ & $\begin{array}{l}\text { Framework for patient } \\
\text { centred communication } \\
\text { (Epstein \& Street) }\end{array}$ & $\begin{array}{l}\text { Six function model of } \\
\text { medical } \\
\text { communication }\end{array}$ \\
\hline 1 & & $\begin{array}{l}\text { Develop, maintain \& } \\
\text { conclude the relationship }\end{array}$ & Relationship building & Fostering relationships & $\begin{array}{l}\text { Fostering the } \\
\text { relationship(s) }\end{array}$ \\
\hline 2 & Data gathering & $\begin{array}{l}\text { Determine and monitor } \\
\text { the nature of the problem }\end{array}$ & \multirow[t]{2}{*}{$\begin{array}{l}\text { Information exchange: gathering and } \\
\text { giving information }\end{array}$} & \multirow[t]{2}{*}{ Information exchange } & Gathering information \\
\hline 3 & & & & & Providing information \\
\hline 4 & & & Decision making & Making decisions & Decision making \\
\hline 5 & Educating patients & $\begin{array}{l}\text { Carry out education and } \\
\text { implementation of } \\
\text { treatment plans }\end{array}$ & $\begin{array}{l}\text { Giving advice / promoting health } \\
\text { related behavior }\end{array}$ & Enabling self management & $\begin{array}{l}\text { Enabling disease \& } \\
\text { treatment related } \\
\text { behavior }\end{array}$ \\
\hline 6 & $\begin{array}{l}\text { Responding to } \\
\text { patient emotions }\end{array}$ & & Handling emotions & Responding to emotions & Responding to emotions \\
\hline 7 & & & & Managing uncertainty & \\
\hline
\end{tabular}

Fig. 2. Functions of medical communication, its goals and outcomes.

\begin{tabular}{|c|c|c|c|c|c|}
\hline & $\begin{array}{l}\text { Six function model } \\
\text { of medical } \\
\text { communication }\end{array}$ & Goals & Immediate endpoints & $\begin{array}{l}\text { Intermediate (and/or } \\
\text { surrogate) endpoints }\end{array}$ & Long term endpoints \\
\hline 1 & $\begin{array}{l}\text { Fostering the } \\
\text { relationship(s) }\end{array}$ & $\begin{array}{l}\text { Good and effective } \\
\text { relationship }\end{array}$ & $\begin{array}{l}\text { e.g., } \\
\text { + eye contact } \\
\text { + patient participation } \\
\text { - physiological stress measure }\end{array}$ & $\begin{array}{l}\text { e.g., } \\
+ \text { trust } \\
+ \text { sense of rapport } \\
+ \text { satisfaction with consultation }\end{array}$ & $\begin{array}{l}\text { + patient satisfaction } \\
+ \text { patient health } \\
\text { - physician stress and } \\
\text { burn out }\end{array}$ \\
\hline 2 & Gathering information & $\begin{array}{l}\text { Adequate diagnosis and/or } \\
\text { interpretation of symptoms }\end{array}$ & $\begin{array}{l}\text { e.g., } \\
+ \text { explorative behavior } \\
+ \text { expression of patient concerns }\end{array}$ & $\begin{array}{l}\text { e.g., } \\
\text { + adequate diagnosis / treatment } \\
\text { plan } \\
\text { - diagnostic test ordering } \\
\text { - medical errors }\end{array}$ & $\begin{array}{l}\text { + patient health } \\
+ \text { physician } \\
\text { satisfaction }\end{array}$ \\
\hline 3 & Providing information & Good information provision & $\begin{array}{l}\text { e.g., } \\
+ \text { check understanding / explore } \\
\text { prior knowledge } \\
\text { - used of jargon }\end{array}$ & $\begin{array}{l}\text { e.g., } \\
+ \text { recall } \\
\text { + understanding }\end{array}$ & $\begin{array}{l}\text { e.g.r } \\
\text { - patient uncertainty } \\
\text { + patient autonomy }\end{array}$ \\
\hline 4 & Decision making & $\begin{array}{l}\text { Decision based on } \\
\text { information and } \\
\text { preferences }\end{array}$ & $\begin{array}{l}\text { e.g., } \\
\text { check decision making } \\
\text { preference / patient values } \\
+ \text { provide information }\end{array}$ & $\begin{array}{l}\text { e.g., } \\
\text { - decisional conflict } \\
\text { + satisfaction with decision }\end{array}$ & $\begin{array}{l}\text { + satisfaction with } \\
\text { decision } \\
\text { + health }\end{array}$ \\
\hline 5 & $\begin{array}{l}\text { Enabling disease \& } \\
\text { treatment related } \\
\text { behavior }\end{array}$ & $\begin{array}{l}\text { Adequate and feasible } \\
\text { disease and treatment } \\
\text { related behavior }\end{array}$ & $\begin{array}{l}\text { e.g., } \\
\text { address patient motivation and } \\
\text { efficacy }\end{array}$ & $\begin{array}{l}\text { e.g., } \\
\text { + illness related behavior } \\
\text { + treatment adherence } \\
\text { + life style } \\
\text { ? costs } \\
\end{array}$ & + patient health \\
\hline 6 & $\begin{array}{l}\text { Responding to } \\
\text { emotions }\end{array}$ & $\begin{array}{l}\text { Supporting the patient, } \\
\text { enhancing the } \\
\text { communication and } \\
\text { referral where needed }\end{array}$ & $\begin{array}{l}\text { e.g., } \\
\text { + clinician explorative skills / } \\
\text { silence } \\
\text { + patient expression of emotions } \\
\text { ? time constraints }\end{array}$ & $\begin{array}{l}\text { e.g., } \\
\text { + patient sense of support } \\
\text { + treatment of psychopathology }\end{array}$ & $\begin{array}{l}\text { + patient emotional } \\
\text { adjustment } \\
\text { - psychological distress } \\
\text { ? costs }\end{array}$ \\
\hline
\end{tabular}


Haes, H. de, Bensing, J. Endpoints in medical communication research, proposing a framework/ of functions and outcomes. Patient Education and Counseling: 2009, 74(3), 287-294

Fig. 3. The role of theory in medical communication research.

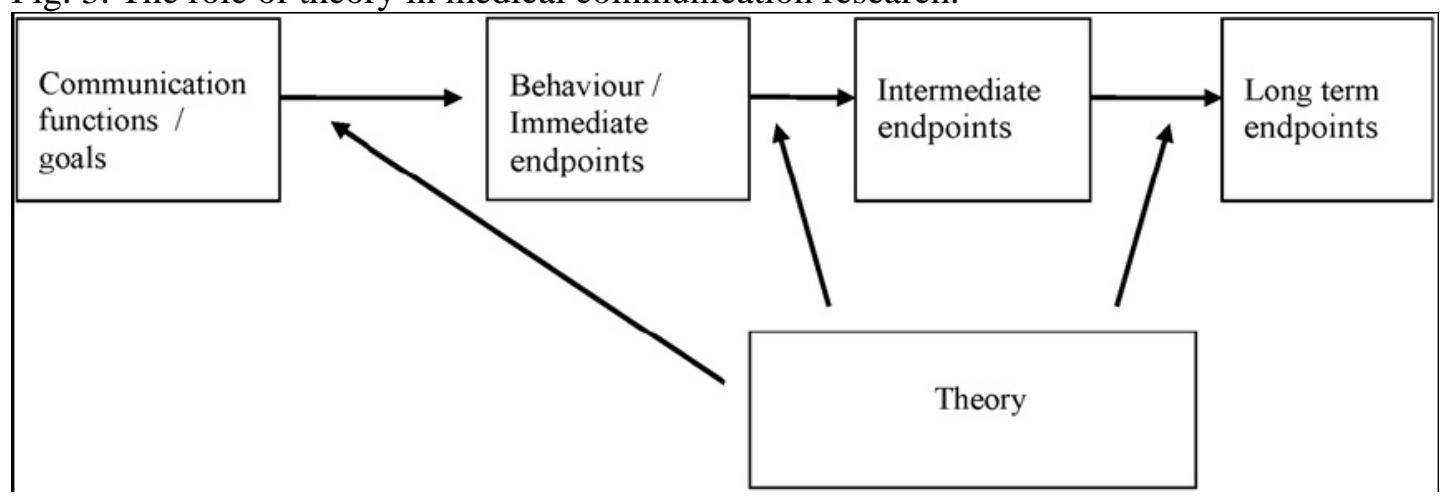

